\title{
Experiencing Graduated Intimacies during Lockdown (Fengcheng)
}

\section{A Reflexive and Comparative Approach to the COVID-19 Pandemic in Urban China}

\author{
Junjie Chen
}

\begin{abstract}
Aвstract: In this article, I examine the ways in which the recent, nationwide 'lockdown' (fengcheng) in China, caused by the unprecedented COVID-19 pandemic, has abruptly reshaped daily intimacy practices of urban residents. Highlighting the lockdown in a southeast coastal city in the broader context of China's post-socialist transformations, I propose that class distinctions have profoundly reconfigured local citizens' daily experiences, producing a system of what might be termed 'graduated intimacies'. To further contextualize these urban citizens' experiences of intimacy under the current transnational geo-biopolitics associated with the pandemic, I provide a reflexive and comparative ethnographic look at the national capital of Beijing. In so doing, I offer a glimpse into the lives of several sets of Chinese citizens at an unexpected historical moment induced by a grave public health crisis extending well beyond China's national borders.
\end{abstract}

KeYwords: China, class distinctions, COVID-19 pandemic, graduated intimacy, reflexivity, comparative method, localised gaze, lockdown

On 9 January 2020, Lihong's father, a man in his early eighties, fell gravely ill from liver cirrhosis and was hospitalised in Yuecheng, ${ }^{1}$ a coastal city in in China's southeast province of Zhejiang. Complementing the intensive care provided by hospital personnel, members of his extended family took turns to remain with the old man in his single-patient room. In this practice, the patient's family was enacting a modern version of a longstanding kinship obligation that rules Chinese family life. In China, companioning with a patient in a hospital room has been a common expectation for patients' families since modern biomedicine became increasingly accessible during the second half of the twentieth century, with a variety of localised sociocultural and practical implications (Zhan 2011, 2018). Expectations have included comforting the patient, offering the patient caring assistance, and, more generally, fulfilling kinship obligations widely accepted across Chinese society.

Unfortunately, such intimate family supports were interrupted by an unexpected nationwide pandemic. Lihong's father may have been one of the last to enjoy his family's hospital companionship. Two weeks after he was hospitalised - on 23 January 2020, just a day before the traditional New Year's Eve festivities - the Chinese state imposed a 'lockdown' (fengcheng) in Wuhan, a metropolis with a population of 11-millionplus in Hubei Province in central China, in order to quarantine an outbreak of COVID-19. As the epidemic-turned-pandemic escalated exponentially, the lockdown was soon extended to the entire province of Hubei, as well as many cities and rural areas across China. In early February 2020, a lockdown was imposed nationwide. Having extended family 
members accompany their relatives during hospital stays was suddenly inconceivable.

In this article, I explore the ways in which a nationwide lockdown resulting from an unprecedented public health crisis has abruptly reshaped the daily intimacies of Chinese citizens. During the past five months, via social media (especially WeChat messaging and videoconference conversations), I have conducted extensive research on the impact of the COVID-19 pandemic on daily intimacies in the coastal city of Yuecheng, as well as in the national capital of Beijing. Drawing on this online fieldwork, I examine how local people's daily experiences of intimate practices during the lockdown were not only transformed profoundly by city governments' omnipresent efforts at surveillance, but have also become entangled with socioeconomic differences that have had serious moral, emotional and political implications.

In developing this project, the ongoing COVID-19 pandemic posed unexpected restrictions on, and challenges for, my research. ${ }^{2}$ The ethnographic data for this article came primarily from Yuecheng, where I have conducted extended fieldwork on other issues since the early 1990s. Early on, I decided to supplement this research by seeking comparative observations from Beijing. Including research from the capital city was crucial for this project, as the central Chinese government began to cope with the implications of the COVID-19 pandemic beyond its national borders shortly after its own, nationwide outbreak came under control in mid-March. The recent resurgence of COVID-19 cases in several districts in Beijing made the metropolis an even more compelling site for further investigation. In incorporating research from these two distinct cities into this analysis, I present complex images of Chinese citizens' intimate experiences of the COVID-19 pandemic.

In the pages that follow, I begin my narrative by foregrounding how ordinary urban families experienced their daily intimacies through cautiously navigating the government's strict regulations and hygiene instructions. As the city administration offices required all citizens to stay at home during the pandemic, daily intimacies were suddenly confined to domestic spaces, which were rather limited in size. I explore how local citizens, while endeavouring to observe home quarantine guidelines, grappled with abruptly imposed city and neighbourhood restrictions in order to acquire daily necessities (especially food and hygiene supplies, the latter being a key to preventing the further spread of the epidemic), to support family members (both emotionally and materially), and to fulfil social obligations beyond their domestic spaces. In examining these quotidian practices, I aim to offer an ethnographic account of local citizens' struggles with maintaining fulfilling experiences of daily intimacy during China's unprecedented COVID-19 pandemic.

In my analysis, I further situate the "lockdown" and its implications for daily life in the broader context of China's post-socialist transformations - transformations that are now evolving into full-blown, class-based distinctions (Anagnost 2008). By contrasting ordinary citizens' confined and stressful daily experiences with those of people who had a variety of privileges regarding access to precious resources during the pandemic, I propose that class distinctions have effectively reconfigured the ways in which the lockdown conditioned local citizens' daily experiences, producing what I would call 'graduated intimacies'. Documenting local citizens' stories of graduated intimacies during the nationwide lockdown, this article offers a glimpse into the conditions under which ordinary Chinese citizens lived during the pandemic, trapped as they were by ever-increasing, class-based social divides in post-socialist China.

\section{Lockdown and the 'Neighbourhood Grid Management System' (Shequ Wanggehua Guanli Tixi)}

When the Chinese state imposed a lockdown in $\mathrm{Wu}$ han at 10:00 am on 23 January 2020, the provincial administration of Zhejiang responded immediately and announced a 'code red' public health emergency the same day. ${ }^{3}$ Yuecheng, a city located in Zhejiang Province, reacted to the COVID-19 crisis even earlier than the provincial government: the day before the provincial administration's proclamation, the city had already confirmed its first COVID-19 case.

On 19 January 2020, a graduate student at a university in Wuhan had returned to Yuecheng, his hometown, for his school's winter break. This young man already felt sick on his way home. Over the next two days, his situation deteriorated. After staying overnight in an observation room of a local 'fever clinic' (fare menzhen) - an outpatient department of the city's major hospital specialising in flu- and feverrelated infectious diseases - he was diagnosed with COVID-19 on 22 January. How did his early case resonate with local perceptions of the disease?

In China, the 2003 SARS (Severe Acute Respiratory Syndrome) outbreak has profoundly shaped popular understandings of severe infectious diseases (Kleinman et. al. 2011; Kleinman and Watson 2005). The 
rapid spread of the disease, the severity of patients' suffering, and the resultant high case fatality rate (CFR) have converged to create a collective perception of SARS as a sort of contemporary 'plague' (wenbing) reminiscent of numerous horrible pandemics that had disastrous death tolls in the nation's historical past. In the decade-and-a-half following the SARS outbreak, a series of global public health epidemics, including the Bird Flu (2003-2005) and the Swine Flu (2009-2010), further consolidated popular discourses that characterised unexpected epidemics as newly emerged forms of wenbing. In turn, this widely received stereotype is deeply entangled with Chinese folk notions of the body, health, and traditional healing. ${ }^{4}$

Seeing that the city's first COVID-19 case had already been confirmed the day before, Yuecheng's municipal leaders responded immediately to the provincial government's announcement of a public health emergency: in the afternoon of 23 January 2020, the city administration warned its citizens about the emerging pandemic. The next morning, city authorities decided to cancel all public celebrations as well as social and religious gatherings scheduled for the upcoming Chinese New Year festivals. This dramatic decision affected virtually all residents of the city.

Around the new millennium, many urban Chinese families had taken advantage of growing nationwide economic prosperity to develop a new holiday tradition for celebrating the new year. Instead of having their 'New Year's Eve Dinner' (Nian Ye Fan) in their own homes, many families began dining out in hotels or fine restaurants with extended family members. Now, with their recent memories of the 2003 SARS outbreak, combined with the prevalent folk notion of wenbing ('plague') associated with the officially announced new pandemic, many Yuecheng citizens realised the imminent threat of COVID-19, and they readily complied with the sudden annulment of the holiday. Based on my online conversations with two journalists, four restaurant managers, and over a dozen local residents, on the evening of 24 January 2020 (Chinese New Year's Eve), I estimate that between 1,600 and 2,000 pre-ordered 'New Year's Eve Dinners' were cancelled. That sudden set of cancellations proved to be a dramatic precursor. Over the next five weeks, the once-crowded, vibrant and noisy city streets and business centres remained empty and quiet.

The confirmation of the first COVID-19 case facilitated a virtual lockdown of Yuecheng. To cut off the spread of the virus, the first student patient was quarantined and hospitalised immediately. His family members, as well as everyone with whom he had recently had contact, were identified and required to stay home for two weeks. The next day (23 January), upon seeing the provincial public health emergency announcement, the 'neighbourhood administrative committee' (shequ guanweihui) - the lower end of the city's hierarchical administration - made a further important move: since the neighbourhood had a confirmed COVID-19 case, the committee imposed a lockdown on the entire neighbourhood, which comprised 1,735 households living in 74 apartment buildings with total number of about 4,574 residents.

This community-level lockdown embodied a governing strategy that the Chinese state had recently enacted to achieve specific policy goals and/or administrative effects. The government coined a term to refer to this new strategy: 'neighbourhood grid management system' (shequ wanggehua guanli tixi). ${ }^{5}$ With the pandemic, government officials easily drew on this new strategy. To contain an outbreak of COVID-19, the neighbourhood administrative committee of Yuecheng implemented two compulsory regulations to put every household into its managerial 'grid'. First, except for the main entrance, all other gates to the affected neighbourhood were closed. The entrance was then fully controlled by the committee. To leave or enter the neighbourhood, all residents were required to have their 'residential ID cards' (jumin shenfenzheng) in hand to verify their identity. Anyone who was not a resident of this neighbourhood was prohibited to enter. Second, to minimise chances of contact infection, the neighbourhood administrative committee asked all the residents to remain in their own apartments during the lockdown. The entire neighbourhood was divided into 35 household groups; each group contained about 50 households. The committee assigned a staff member as the 'liaison person' (lian luo yuan) to each grouping of households; this person was tasked with ensuring that all residents of the household grouping stayed in their own apartments. Every other day, each household was allocated a two-hour time slot during which one family member, who was required to wear a face mask, could leave their apartment to purchase daily necessities in nearby grocery stores. Through these measures, the neighbourhood authority endeavoured to quarantine the spread of COVID-19.

On 25 January 2020 - Chinese New Year's Day the city administration announced that Yuecheng had just diagnosed the second case of COVID-19 in a resident who had also travelled recently to Wuhan. To prevent a major outbreak of COVID-19, the government immediately mobilised its staff to identify everyone, amongst the city's one-million-plus resi- 
dents, who had either visited Wuhan (the metropolis in which the COVID-19 pandemic is thought to have originated) or had contact with anyone from Wuhan during the previous two weeks. Meanwhile, the city authority asked every neighbourhood administrative committee across the entire municipality to implement a compulsory neighbourhood grid management policy.

Throughout the entire COVID-19 pandemic, such neighbourhood grid management strategies were widely practised across China. In the end, the strategy contributed significantly to the Chinese state's effective mitigation of the pandemic. More recently, starting from 11 June 2020, the Beijing municipal administration has once again adopted the grid management approach to cope with newly identified COVID-19 cases in a number of local communities.

Effective though they were in containing the virus, these extensive, compulsory measures came at a steep cost - a human cost. I discuss this human cost in the following sections.

\section{Everyday Intimacies under the Localised Gaze}

Despite the Wuhan lockdown, the pandemic escalated rapidly across China. Via WeChat and Weibo the two most popular social media channels in China, with hundreds of millions of users - numerous pictures, videos clips, and narratives of Chinese citizens' experiences of suffering during the lockdown came to circulate widely on people's smartphones. In late January 2020, as the number of COVID-19 cases quickly exceeded the nation's entire number of confirmed SARS cases in 2003, COVID-19 was increasingly seen on social media as a new wenbing: a potent source of invisible 'pollution' that could travel capriciously through air or wind to contaminate unprotected, healthy citizens nearby.

In Yuecheng, the number of confirmed COVID-19 cases increased slowly. By 15 February 2020, the city announced a total of 11 confirmed cases without a single death. Nevertheless, the relatively small number of confirmed cases did not challenge local people's perception of COVID-19 as a newly revived plague, a source of vicious, transmittable illness that might cause disastrous damage to the human body. Many Yuecheng residents thought that COVID-19's potential destructive power to the human body would be comparable to that of SARS. They cited a number of follow-up media reports to substantiate their conviction: during the 2003 pandemic, SARS patients, even if they eventually recovered from the infection, might suffer severe, long-time sequelae, including pulmonary fibrosis and osteoporosis. Local residents believed that the current COVID-19 epidemic would very likely cause similar, indelible harm to human health.

On 31 January 2020, a story of a recent COVID-19 case came to circulate widely on local social media. In Ningbo, a nearby port city in Zhejiang Province, a vegetable seller who managed a small business in a local food market was diagnosed with COVID-19. Soon thereafter, 11 related cases were confirmed. The social media story detailed how these 11 people had contacted the virus: after epidemiological tracing, it said that they were very likely all caused by the same vegetable seller. In the next few days, this story remained one of the hottest topics in local social media discussions: it was said to have demonstrated once again how potent the COVID-19 virus was in transmitting itself, and how vulnerable a person could be even if he or she wore face masks and did not have direct contact with a COVID-19 patient in the food market. This story remained a major topic on WeChat for over a week amongst residents of Yuecheng.

At first, Yuecheng residents viewed COVID-19 patients as victims of the ongoing pandemic, and they were sympathetic to these patients. However, as the pandemic escalated across the nation and the threat of the disease lurked around their own neighbourhoods, COVID-19 patients were increasingly perceived as carriers of a vicious infectious disease. Subsequently, in local residents' perceptions, the perception of these COVID-19 patients experienced a drastic symbolic twist: from being viewed as generic victims of an ongoing pandemic towards becoming stigmatised targets who were seen as causing an escalating local public health crisis. As Mary Douglas (1966) might put it, COVID-19 patients were perceived as a symbolic danger that risked polluting the health of the neighbourhood.

In Yuecheng, soon after a COVID-19 patient was confirmed, the municipal news office would announce the case. Although the patient's name, marital status, and residential apartment number were concealed, the office would publicise information about the patient's age and gender, as well as the name of the patient's neighbourhood and the location of the patient's residential building. In sharing this information, the city administration hoped to warn other residents about the potential infection risks in and around the neighbourhood where the patient resided.

Yet from the officially released information, local people could easily identify the patient as well as his 
or her family members; such 'private' information soon circulated on social media. Following the lockdown of neighbourhoods, the escalating pandemic in Yuecheng and nearby cities resulted in growing panic amongst local residents. ${ }^{6}$ During the first week of lockdown, for example, that first COVID-19 patient (the graduate student who came home from Wuhan) was soon blamed for bringing the virus to his hometown. He was identified immediately, and personal information about him as well as his family members was quickly publicised on social media. As a result, the patient and his family members were under the intensive gaze of their neighbours (cf. Foucault 1973). Deemed as carriers of the COVID-19 virus and a threat to public health, the student's entire family was isolated by its community. His family members were instantly avoided by their neighbours; their activities were constantly monitored by local officers; and they were virtually excluded from the local society. His parents had to bear extreme social pressure while worrying about their son's recovery status in the hospital.

To avoid a major outbreak of COVID-19, local residents cooperated with the city administration's neighbourhood grid management guidelines and complied with the government's requirements to stay home during the lockdown. One reason for this cooperation is that, through social media, local residents became aware that potential COVID-19 carriers might escape screening if they did not exhibit any symptoms. To avoid the risk of coming into contact with such potentially contagious individuals, Yuecheng residents accepted home quarantine as the most effective means to protect themselves during the pandemic.

During the lockdown, in both the coastal city of Yuecheng and the national capital of Beijing, daily intimacies thus suddenly became confined to domestic spaces. In Yuecheng, residents were strictly required to stay at home, with only two exceptions: grocery shopping and medical visits.

At the neighbourhood entrance gates, residents who were allowed to leave the neighbourhood for one of those two reasons were required to present their 'residential ID card' (jumin shenfenzheng), have their body temperature checked, and register the time of their departure. On their return, the residents had to repeat the same procedure at the entrance to the neighbourhood. Anyone who was found to have a body temperature beyond the normal range would not be allowed to enter or leave the neighbourhood. This person would be tracked down, and then be subject to a series of screening tests. In case follow-up tests continued to yield abnormal results, this person would be categorised as a 'suspected patient' (yisi bingren) and immediately sent to a local hospital.

What impacts did these drastic measures have on vulnerable individuals unable to fend for themselves?

\section{The Case of Xiaoyue and Her Elderly Father}

While urban Chinese residents endeavoured to observe the rigorous home quarantine guidelines just outlined, the compulsory measures posed challenges to many households who needed help beyond the confined domestic space. A widower in his mideighties, Mr. Zheng lived alone in an apartment in Yuecheng after his wife passed away in the summer of 2019. He had a married daughter, Xiaoyue, who lived in a nearby neighbourhood. Before the pandemic, Xiaoyue came to see her father every evening and did the grocery shopping twice a week for him; this had been an established routine for nearly a decade. The unexpected lockdown interrupted the elderly man's daily life in significant ways.

Xiaoyue recognised that her father was unable to shop for daily necessities himself. At his advanced age, Mr. Zheng was highly vulnerable to the virus; moreover, he did not have a single face mask at home. In this, he was hardly alone. Before the national government suddenly announced the COVID-19 pandemic on 21 January 2020, most Chinese citizens were unaware of the imminent public health crisis, and many lacked any epidemic prevention supplies such as face masks and hand sanitiser.

Xiaoyue herself had her own challenges beyond caring for her father. As a staff member of a local government office, she volunteered to check local residents' body temperatures at neighbourhood entrances during the lockdown, working five shifts a week for four hours per shift. From her volunteer work during the first month of the lockdown, Xiaoyue received only one face mask each week from the municipal administration. After completing each shift and returning home, Xiaoyue had to spray disinfecting alcohol on the face mask and hang it on her balcony for re-use during her next four shifts. As I learnt from my conversations with dozens of local residents, Xiaoyue's disinfecting practice echoed that of many others. During the first several weeks of the lockdown, many ordinary Chinese citizens had to re-use epidemic prevention items, due to supply shortages. Thankfully, the supply increased significantly in late February. Benefitting from this national development, Xiaoyue was able to receive a mask for 
each shift she worked in the remaining weeks of the lockdown.

Having introduced Xiaoyue's background, I would now like to explore how Xiaoyue managed to provide daily necessities for her elderly father. Xiaoyue grew up in her parents' neighbourhood. After she married in 1995, Xiaoyue lived in a nearby neighbourhood several blocks away from her parents. In the last two-and-a-half decades, her parents had helped raise her child and, as I mentioned above, she came to see her parents almost every evening. During the past several decades, Xiaoyue knew several generations of her father's neighbourhood's administrative staff members. With years of mutual familiarity, Xiaoyue discussed her father's situation with neighbourhood committee members over the phone; she was allowed to send grocery items to her father once a week.

The phone conversation between Xiaoyue and the neighbourhood officers was brief. The implications underlying that discussion, however, were rather rich. In Chinese folk ethics, 'filial piety' (xiaoshun) reverence for and taking good care of elderly parents - is considered the prime virtue. In everyday life, practising filial piety means fulfilling both social expectations and moral obligations. Moreover, practising filial piety might also contain a sense of spiritual transcendence, as it implies one's pursuit for moral perfection by overcoming various mundane challenges and material difficulties (Chen and Chen 1998; Fong 2004).

Xiaoyue's conversation with neighbourhood committee officers encapsulated the delicate 'cultural intimacy' of Chinese social relationships (Herzfeld 1997). In his current daily life, Xiaoyue's elderly father obviously needed extra assistance beyond that which he could get in his confined domestic sphere. On Xiaoyue's side, helping her elderly father with groceries would constitute practising a form of filial piety - a behaviour that embodies a prime Chinese virtue, especially in difficult times. With this compelling combination of practical needs (food, hygiene) and kinship moralities, the neighbourhood officers found it difficult to decline Xiaoyue's request; they ended up granting her an exception.

Beyond daily ethics, 'cultural intimacies' also became entangled with the Chinese notion of the social network (Yan 1996; Yang 1994). Through years of acquaintance, Xiaoyue and the neighbourhood officers were not strangers to each other. Indeed, this foundation allowed them to develop a close social relationship. Probably more importantly, Xiaoyue's potential connections to state power - resulting from her current position - facilitated her negotiation with neighbourhood officers. For the moment, the neighbourhood officers were managing community affairs during the lockdown. In the future, however, the neighbourhood officers might need a favour from Xiaoyue, as she works at a resourceful government office. Thus, the officers' granting of an exception to allow Xiaoyue to enter her father's neighbourhood would surely make her grateful to them, creating a space for their future reciprocal interactions.

With such an exception, Xiaoyue was able to fulfil her filial obligations to her widowed father during the nation's unprecedented COVID-19 pandemic. Nevertheless, from her father's perspective, the new routine was far from optimal. Compared with his previous daily life, the elderly man's familial intimacy with Xiaoyue was suddenly confined to very limited domestic spaces, and with only a single, short time slot on a weekly basis. Even so, both the material and emotional support the elderly man was able to receive from his daughter contained invisible yet perceptible elements of privilege: in the makings of these forms of support, his daughter's government position, and its concomitant middle-class distinctions (as Bourdieu [1984] might term them) facilitated her negotiation with neighbourhood officers, allowing her to achieve modest levels of exceptional privileges.

If a relatively low-level government worker was able to receive these sorts of dispensations, what opportunities might higher-level government workers attain?

\section{Social Distinctions and the Makings of Graduated Intimacy: The Case of Lihong's Father}

As I suggested in the vignette I offered at the opening of this article, the outbreak of the COVID-19 pandemic interrupted an extended family's routine to tend to their elderly father in the hospital. Along with the government's lockdown regulations, the hospital offered two options to in-patients' families during the COVID-19 crisis. The first was that an inpatient could have a single family member as his or her companion in the sickroom. To reduce the chance of cross-infection, this family member was not allowed to engage in the 'normal' practice of taking turns with other family members to accompany their hospitalised relative; instead, she or he had to stay with the in-patient full-time, until the in-patient was discharged from the hospital. The second was that a family could hire a full-time care worker through 
the hospital. If a family chose this option, they had to leave their relative 'alone' in the hospital - no family member was allowed to visit the patient during the lockdown.

In the case of Lihong's extended family, both options stood too far away from their expectations. In the past five years, Lihong's father had been hospitalised 11 times, due to chronicle illness in his liver and stomach. His condition was deteriorating slowly but steadily. His doctors said that the old man might have two to three months of time remaining. This might be his last hospital stay in his life.

With such a prognosis in mind, the extended family hoped to spend whatever time on earth remained for the old man with one or another relative by his side. They mobilised their powerful connections to achieve just such an outcome.

Two decades earlier, Lihong's father had retired from a powerful position as director of a municipal government office. With his power and connections, all of his three children had acquired resourceful jobs, and they married quite well in terms of wealth and social status. The husband of Lihong's younger sister, for example, has been successful in climbing up the local bureaucratic ladder; he was now (at the time of the pandemic) the mayor of an economically vibrant township in Yuecheng. Put simply, Lihong's extended family was part of the local elite.

With the help of a city government leader, the hospital accommodated the family's request for an exemption from the normal COVID-19 hospital visit regulations. Through the hospital, the family hired not one but two experienced care workers. Each worker took a 12-hour shift every day, and they took turns taking care of the old man. ${ }^{7}$ To reduce chances of cross-infection, neither care worker was allowed to leave the hospital during the lockdown.

As for Lihong's extended family, they were permitted to have up to three people come to visit Lihong's father each day, and they could stay overnight. To reduce the chance of cross-infection, the family purchased five sets of expensive medical protective clothing (including protective coveralls and goggles) as well as several packs of N95 respirators, disposable gloves, and hand sanitiser from the hospital. How did they manage to procure such luxuries?

As I mentioned above, during the initial weeks of the lockdown almost every hospital and clinic in China faced a shortage of epidemic prevention supplies. As we saw in the previous section, Xiaoyue, a staff member at a local government office, was allocated only one face mask per week for her five shifts of volunteered public service. Thus, when
Lihong's younger sister talked easily with me over a video WeChat conversation about how her family had acquired expensive medical protective suits, I was amazed.

During two months of lockdown, Lihong's father received high-quality medical care at the hospital and constant attention from his two privately hired care workers. His extended family, comprising his wife, his three adult children and their spouses, and his grandchildren, kept him company frequently. During his entire 100-day-long stay in the hospital, Lihong's father did not have to eat mediocre meals prepared by the hospital cafeteria. Instead, his children and grandchildren cooked and brought meals for him that catered to his taste.

Lihong had feared that her father might pass away during the lockdown. According to the city's compulsory regulations, anyone who passed away during the lockdown was not allowed to have a regular funeral and ritual services. Instead, the body had to be cremated the next day, and only the immediate family members could escort the corpse to the crematorium. During the lockdown, mortuary services for the dead were minimised to next to nothing.

With the high-quality care he received from both the hospital and his extended family, Lihong's father survived the lockdown. The city ended the lockdown and re-opened services and businesses on 26 March 2020. Lihong's father passed away on 18 April. The old man's funeral was held on 20 April 2020. About 140 people attended.

The hospitalisation of Lihong's father illustrates how social distinctions - embodied through power, wealth and connections - profoundly shaped people's daily experiences during China's unprecedented COVID-19 pandemic. In effect, the pandemic produced what amounted to a system of graduated intimacy. As an elderly man with severe illness, Lihong's father had high-quality experiences of intimacy with his extended family at the last stage of his life during the nationwide lockdown. Compared with Lihong's father's experience, Xiaoyue's experience with her widowed father looked apparently ordinary. As a staff member at a local government office, Xiaoyue was allowed certain privileges during the neighbourhood lockdown, which made her experience with her father above average. Although Xiaoyue and her father were by no means connected to the local elites, they belonged to the local middle class. They were able to draw on their stable (if not luxurious) financial footing and their solid (if not eminent) social status to attain modest privileges that were in theory forbidden under the lockdown. 
What happened to families without any such connections to the power structure in broader and more complex national and transnational situations?

\section{Transnational Geo-Biopolitics and Urban Citizens' Experiences of Intimacy: The Case of Jianjun's Father}

To provide a counterweight, if you will, to the previous two cases, I would like to consider a more recent story from the national capital of Beijing. In evoking this narrative, I aim to counter received notions about middle-class intimacy and further complicate our understandings of urban Chinese citizens' experiences of intimacy under the broad national agenda and global geo-biopolitics associated with the ongoing COVID-19 pandemic.

On 22 April 2020, Jianjun's father, a man in his late seventies, was hospitalised. In 1997, Jianjun's father had been diagnosed with stomach cancer and had surgery soon thereafter. Now, some 23 years later, Jianjun's father began feeling unwell around his stomach. Jianjun worried that there might be some pathological changes in his father's stomach. He sought out gastroenterologists and scheduled a hospital visit for his father. After a series of exams and tests, Jianjun was told that his father had another kind of stomach cancer that had already spread to other organs. He would need to remain in the hospital for an undetermined period of time.

Realising that his father might only have a few months left, Jianjun immediately informed his older sister, who had immigrated to Canada at the turn of the new millennium. Meanwhile, Jianjun hired a care worker to take care of his father full time in the hospital. In late April, the COVID-19 pandemic in Beijing was well under control. Yet the hospitals continued to restrict the flow and number of patients. Jianjun followed the hospital's guidelines carefully while trying to visit his father as frequently as possible. Meanwhile, his sister managed to acquire a visa from the Chinese Embassy in Toronto and booked an expensive two-stop flight home.

The siblings' sincere hope for a three-way reunion with their father during his remaining days was crushed by an unexpected resurgence of COVID-19 in Beijing on 11 June 2020. In Jianjun's apartment building, a resident tested positive for COVID-19. Jianjun was required to stay home for 14 days; during these days, he was not allowed to visit his father. Five days later, his sister arrived in Beijing; she had to go through a 14-day quarantine period in a hotel on the outskirts of the metropolis, which was arranged by the Beijing municipal administration.

Over the next few days, Jianjun's father's condition deteriorated quickly. After appealing to the hospital several times, Jianjun was finally granted an exception to the compulsory 14-day self-quarantine requirement. On the afternoon of 20 June, with a negative result from a nucleic acid amplification test for COVID-19 held at a nearby hospital the previous day, combined with his continued normal daily health results (including body temperature and other symptoms related to COVID-19) during his nine-day home quarantine, Jianjun was allowed to visit his father. On the morning of 21 June 2020, the old man passed away without the companionship of his two children.

Due to the resurgence of the COVID-19 pandemic, Jianjun's family was unable to offer a memorial service to the deceased. Jianjun, his wife and their young daughter escorted the corpse to the crematorium. Jianjun's sister was still under quarantine and was unable to join them. She said farewell to her father virtually via WeChat video from the hotel at which she remained quarantined.

This poignant story stands in stark contrast to the first two narratives shared above. Compared with those other two families (one middle-class and one elite) in Yuecheng, Jianjun's family was urban and middle-class and living in the national capital. Yet, lacking close connections with powerful government officials, Jianjun's family was unable to mobilise effective arguments to grant them exceptions to the hospital visitation rules. In that sense, Jianjun's story complicates common perceptions of middle-class Chinese experiences of intimacy: that even amongst the middle class, privileges are unequal, depending on the level of status that individual families have due to connections to government institutions and officials. In this case, the family's situation was further aggravated by the current transnational geo-biopolitics associated with the COVID-19 pandemic. Having declared victory over its domestic pandemic, the Chinese state is now energetically coping with COVID-19 beyond national borders. Ordinary middle-class families such as Jianjun's were immediately submerged by the state's grand plans. Their feelings - dreams, pains and regrets - disappeared into oblivion, inundated and silenced by the state's ongoing grand narrative of its claimed success in containing the pandemic at home while the outside world remains besieged by the COVID-19. 


\section{Conclusion: A Reflexive and Comparative Approach to Intimate Experiences of Pandemic}

In this article, I have examined the ways in which a nationwide lockdown caused by the COVID-19 pandemic has abruptly reshaped daily intimate practices of a range of Chinese citizens. I began my narrative by foregrounding how ordinary urban families experienced their daily intimacies while cautiously navigating the government's strict regulations and quarantine instructions. I explored how residents grappled with abruptly imposed city and neighbourhood restrictions as they endeavoured to acquire daily necessities, support family members, and fulfil various moral, emotional and social obligations beyond their domestic spaces.

In my ethnographic analysis, I situated the lockdown's implications for daily intimacies in the broader context of China's post-socialist transformations. By contrasting ordinary citizens' confined and stressful daily experiences with those who were able to mobilise a variety of privileges to readily access precious resources during the pandemic, I proposed that class distinctions effectively reconfigured the ways in which the lockdown conditioned local citizens' daily experiences, producing what I have characterised as a system of graduated intimacies. To complicate received notions about middle-class intimacy, I narrated one family's poignant experience in the national capital. From this story, I hoped to further enrich our understandings of urban Chinese citizens' experiences of intimacy under the state's current broad and complex national agenda and in the context of the global geo-biopolitics associated with the ongoing COVID-19 pandemic.

The dramatic three-way comparison I have provided above of three urban Chinese families' intimate practices during the lockdown might seem to serve as a poster child of sorts for the classic RadcliffeBrownian 'comparative method' (Radcliffe-Brown 1951). Yet this seemingly old-fashioned 'controlled comparison' actually entailed an ethnographic approach that Michael Herzfeld might term 'reflexive comparativism' (2001: 259), both theoretically and ethnographically. In this article, I began my narrative based on engaged extensive ethnographic fieldwork, with a constant humanistic concern about the impacts of the current COVID-19 pandemic on ordinary Chinese citizens' daily lives. In developing my analysis, I approached the pandemic through intersecting socio-cultural and politico-economic valences entrenched cultural values, hegemonic government policies, evolving social differences (embodied through power, wealth and connections), as well as national and transnational geo-biopolitics - at the local, national and global levels. Linking ethnographic comparisons with multi-scope theoretical reflexivity - which Herzfeld (2001) has insightfully argued is increasingly central to an empirical understanding of social and cultural phenomena - I hope the reflexive comparative approach that this article has developed might help illuminate contemporary issues such as global health crises, inequality caused by class differentiations, and governmentality challenges. As such, in presenting three contrasting narratives chronicling diverse experiences of lockdown, this article has offered a glimpse into the human condition of Chinese citizens occupying different echelons of the socioeconomic and power hierarchy at an unexpected historical moment induced by a grave public health crisis occurring both within and beyond China's national borders.

\section{Acknowledgements}

I am grateful to my friends and consultants in China's coastal city of Yuecheng and in the national capital of Beijing for sharing with me their personal life stories during the COVID-19 pandemic. I would like to thank my friends both in China and overseas for sending me numerous social media stories about the pandemic. Amongst my ever-supportive colleagues at Minzu University of China, I would particularly like to thank Dr. Haoqun Gong for generously sharing with me an invaluable research document that she and her research team members have created to carefully chronicle both national and regional events and policy announcements associated with the COVID-19 pandemic in China. Last, but not least, I am grateful to Dr. Alma Gottlieb as well as two anonymous reviewers for reading my drafts and providing me with insightful feedback.

Junjie Chen is Professor of Anthropology at Minzu University of China. He has conducted extensive research on gender and reproductive health policy and technology as they intersect with socioeconomic transformations, with a regional focus on China / East Asia in broader globalising, transnational, and diasporic contexts. His current research interests include global health, state and society, globalisation and transnationalism, and the connection between gender, fertility and migration.

E-mail: junjiechen2012@gmail.com 


\section{Notes}

1. In this article, I use pseudonyms to protect all consultants and conceal all local places mentioned. Yuecheng is a pseudonym for the coastal city in which I have conducted ethnographic research since the early 1990s. An economically vibrant city in Zhejiang Province in southeast China, in 2019 Yuecheng had a total population of $1,142,000$.

2. For conducting ethnographic research during the ongoing global COVID-19 pandemic, anthropologist Magdalena Goralska (2020) has recently offered insightful analysis and practical advice.

3. http://gongyicovid19.custom.lingxi360.com/index .php?order=asc.

4. Historian Nathan Sivin and anthropologists Lili Lai and Judith Farquhar have provided insightful discussions on Chinese folk notions of body, health and traditional healing (see Sivin 1987; Farquhar 1994, 2013; and Lai and Farquhar 2015).

5. http://theory.people.com.cn/n/2014/1127/c4053126105462.html.

6. In their recent study of the COVID-19 pandemic in China, anthropologists Gao Bingzhong and $\mathrm{Ma}$ Qiang (2020) developed an analytical concept, 'societal fragility' (shehui cuiduan), to theorise the wildly chaotic situations in Wuhan caused by the sudden lockdown of the metropolis in late January 2020.

7. In Yuecheng, due to insufficient government funding, public hospitals were seriously short-staffed with nurses. Local hospitals hence permitted private care workers to work for in-patients with various needs. However, most of these care workers were not professionally trained, nor were they affiliated with local hospitals. To be permitted to work in local hospitals, these care workers had to pay a fee 50RMB-80RMB/day, equivalent to about \$7-\$12/ day per person - to the hospital. Thus, coordinating care workers to work for in-patients has become a source of informal income for local public hospitals in Yuecheng. The situation in Yuecheng speaks to the grave funding realities that many public hospitals are now facing across China. For a general study comparing nursing care between China and the United States, see a recent study by Beatrice Kalisch and Yilan Liu (2009).

\section{References}

Anagnost, A. (2008), 'From "Class" to "Social Strata": Grasping the Social Totality in Reform-Era China', Third World Quarterly 29, no. 3: 497-519, doi:10.1080/ 01436590801931488.
Bourdieu, P. (1984), Distinction: A Social Critique of the Judgment of Taste, (trans.) R. Nice (London: Routledge).

Chen, J., and Z. Chen (1998), 'Rethinking Fei Xiaotong's Theoretical Model of Guanxi in Chinese Society: A Sociological Critique' [In Chinese], Social Sciences Front 16, no. 1: 197-204.

Douglas, M. (1966), Purity and Danger: An Analysis of Concepts of Pollution and Taboo (London: Routledge).

Farquhar, J. (1994), Knowing Practice: The Clinical Encounter in Chinese Medicine (Boulder, CO: Westview Press).

Farquhar, J. (2013), 'Chinese Medicine as Popular Knowledge in Urban China', in Chinese Medicine and Healing: An Illustrated History, (eds) L. Barnes and T. J. Hinrichs (Cambridge, MA: Harvard University Press), 272-274.

Lai, L. and J. Farquhar (2015), 'Nationality Medicines in China: Institutional Rationality and Healing Charisma', Comparative Studies in Society and History 57, no. 2: 381-406, doi:10.1017/S0010417515000079.

Fong, V. (2004), 'Filial Nationalism among Chinese Teenagers with Global Identities', American Ethnologist 31, no. 4: 629-646. https://www.jstor.org/ stable/4098872.

Foucault, M. (1973), The Birth of the Clinic: An Archaeology of Medical Perception, (trans.) A. Sheridan (New York: Routledge).

Gao, B. and Q. Ma (2020), 'Constructing Societal SelfOrganisation and Nurturing Social Resilience in Epidemic Prevention and Disaster Relief' [in Chinese], Journal of Guangxi University for Nationalities (Philosophy and Social Science Edition) 42, no. 1: 41-45.

Goralska, M. (2020), 'Anthropology from Home: Advice on Digital Ethnography for the Pandemic Times', Anthropology in Action 27, no. 1: 46-52, doi:10.3167/aia.2020.270105.

Herzfeld, M. (1997), Cultural Intimacy: Social Poetics and the Real Life of States, Societies, and Institutions (New York: Routledge).

Herzfeld, M. (2001), 'Performing Comparisons: Ethnography, Globetrotting, and the Spaces of Social Knowledge', Journal of Anthropological Research 57, no. 3: 259-276, https://www.jstor.org/stable/3631423.

Kalisch, B. J., and Y. Liu (2009), 'Comparison of Nursing: China and the United States', Nursing Economics 27, no. 5: 322-331, https://pubmed.ncbi.nlm.nih .gov/19927447/.

Kleinman, A., and J. L. Watson (eds) (2005), SARS in China: Prelude to Pandemic? (Stanford, CA: Stanford University Press).

Kleinman, A., Y. Yan, J. Jun, S. Lee, E. Zhang, P. Tianshu, W. Fei, and J. Guo (2011), Deep China: The 
Moral Life of the Person (Berkeley: University of California Press).

Radcliffe-Brown, A. R. (1951), 'The Comparative Method in Social Anthropology', Journal of the Royal Anthropological Institute of Great Britain and Ireland, 81, no. 1: 15-22, doi:10.2307/2844014.

Sivin, N. (1987), Traditional Medicine in Contemporary China: A Partial Translation of Revised Outline of Chinese Medicine (Ann Arbor: University of Michigan Center for Chinese Studies).

Yan, Y. (1996), The Flow of Gifts: Reciprocity and Social Networks in a Chinese Village (Stanford, CA: Stanford University Press).
Yang, M. M. (1994), Gifts, Favors, and Banquets: The Art of Social Relationships in China (Berkeley: University of California Press).

Zhan, M. (2011), 'Human Oriented? Angels and Monsters in China's Health-Care Reform', East Asian Science, Technology, and Society: An International Journal 5, no. 3: 291-311, doi:10.1215/18752160-1347620.

Zhan, M, (2018), "Cosmographic Experiments: Thinking, Doing, and Being with Classical Chinese Medicine." Humanities Futures. https://humanitiesfutures .org/papers/cosmographic-experiments-thinking-doi ng-and-being-with-classical-chinese-medicine/ 